was also exhibited in experiments with human albumen labelled with radioactive iodine. The labelled protein was eliminated slowly and continuously from the tolerant animals, in contrast to the controls, which exhibited a sharp rise in the rate of elimination as the immune response developed. Tolerance in this instance was shown to be specific, by means of cross-tests with tobacco mosaic virus and also diazotized human albumen. The diazotized human albumen provides a refined demonstration of specificity, since it is an antigen which normally elicits antibodies of two distinct types, specific either for the diazo group or for the albumen. Those tolerant animals which responded to the diazotized human albumen produced antibody only against the diazo group, as could be shown by absorption tests with human albumen. In a single animal, administration of diazotized human albumen appeared to weaken the tolerance to normal albumen, indicating that the state of tolerance can itself be modified experimentally.

Applications of immunological tolerance were deseribed in papers entitled "Tolerance of Ascites Tumour Cells", by H. Koprowski (Lederle Laboratories, New York), and "Acquired Tolerance of the Rous Sarcoma Agent in Turkeys", by R. J. C. Harris (Chester Beatty Research Institute). Koprowski was able to obtain, from two transplantable mouse lymphomas, lines that would grow in normally resistant mouse strains; and from a rat hepatoma he obtained a line which would grow in mice. The transformation was made by inoculation of tumour cells into unborn mice of the prospective host strain, thus inducing a state of tolerance which enabled the tumour to grow progressively. The tumour masses which developed after birth served to start the transformed line of tumour, if necessary re-inoculating fotal mice to complete the transformation. The adaptation of the transformed tumour lines to their new hosts was incomplete, as judged by the dosage of tumour cells needed to kill the new hosts as compared with hosts of the strain of origin. The transformed mouse-tumour lines appeared to retain antigens characteristic of their strains of origin, as indicated by adoptive immunization tests. The rat tumour retained the characteristic rat $V$-chromosomes, and could be transplanted back into rats. In tests with a variety of animal viruses, the transformed-tumour lines appeared to provide better hosts for virus multiplication than the original lines, and to be more susceptible to oncolysis by viruses.

Turkeys which had been rendered partially tolerant to chicken antigens were used by Harris, in an attempt to separate the Rous sarcoma agent from chicken antigens. If inoculated soon after hatching with chicken antigens, a proportion of turkeys are rendered susceptible to the Rous sarcoma virus and other non-virus chicken sarcomas. Live blood cells, blood cells killed by freezing or heating, or skin grafts, are all active for this purpose as chicken antigens. While growing in susceptible turkeys, the Rous sarcoma progressively loses its content of virus infective in chickens. This may indicate a conversion of the virus to the turkey antigenic type ; but since virus assays were not also carried out in turkeys, it may instead indicate a decrease in the virus content of the tumour cells. After a single passage back into chickens, the sarcoma regains its full content of virus infective in chickens.

Parallel papers were presented by $M$. Hašek (Czechoslovakian Academy of Science) on "Tolerance Phenomena in Birds", and by R. E. Billingham and L. Brent (University College, London) on "Analysis of Tolerance induced in Newly Hatched Turkeys and Chicks". Work in London and Prague has shown that tolerance is readily produced in birds by the introduction of foreign cells into the embryo, intravenous injection and parabiosis being particularly effective methods. Hašek concentrated on the manifestation of tolerance as a suppression of hæm. agglutinin production, and Billingham and Brent as a prolongation of the survival-time of skin grafts. In order to weaken or suppress reactivity to skin homografts, Billingham and Brent find that live, nucleated cells are essential. According to the criteria of hæmagglutinin suppression and prolonged graft survival, tolerance is produced more readily within than between species. The combinations of species tested were between chicken, turkey, duck, pheasant, goose, guinea fowl and pigeon. As expected on Darwinian principles, they find that tolerance produced between some strains of poultry is weaker than between others. The degree of tolerance which could be produced between species appeared to vary in accordance with their systematic relationship.

Induction of tolerance by intravenous injection of antigens into new-born chickens or mice was also described by Billingham and Brent. This method proved to be more economical than injection into the embryo. Nearly half the chickens injected with blood from another strain exhibited a degree of tolerance, although only a small proportion of skin homografts on new-born chickens take permanently. This discrepancy is ascribed to the delay in vascularization of the grafted skin.

${ }^{1}$ Nature, 178, 852 (1955).

\title{
OBITUARIES
}

\section{Prof. F. Riesz}

THE distinguished Hungarian mathematician, Friedrich (Frigyes) Riesz, died recently. He was born on January 22, 1880, at Györ, and studied at Zurich, Budapest, Göttingen and Paris, taking his doctor's degree at Budapest in 1902. In 1911 he was appointed to a supplementary professorship at Kolozsvár (Cluj), becoming Professor Extraordinarius in 1912 and Professor Ordinarius in 1914. In 1919 Riesz moved with his university to Szeged, and in 1945 he was appointed to a chair in Budapest. In 1922 he became editor of a newly founded periodical, the Acta Scientiarum Mathematicarum of Szeged, which quickly established a distinguished place for itself among the world's mathematical journals.

Riesz was one of the pioneers of functional analysis, and we owe to him many of the fundamental ideas of the subject, which were later incorporated in an axiomatic formulation by S. Banach and his collaborators. Riesz's principal contributions may be summarized as follows : the Riesz-Fischer theorem (1907) on the equivalence of Hilbert's space of sequences of convergent sum of squares with the space of functions of summable square, which is the mathematical basis of the equivalence of matrix 
mechanics and wave mechanics; the Stieltjes integral representation for linear functionals on the space of continuous functions (1909); the theory of $L^{p}$ spaces (1910); the first systematic discussion of analytic functions of operators (1913); the definition and properties of general completely continuous operators (1916); and the foundation of the theory of partially ordered vector spaces (1928). In 1952 there appeared the "Leçons d'analyse fonctionnelle", written jointly with B. Sz.-Nagy, and easily the most readable introduction to functional analysis that has yet appeared.

Riesz constantly strove to simplify the presentation of the theory of the Lebesgue integral; he introduced the systematic use of step functions (1912), and he proved (1931) the famous 'rising sun lemma', which leads to an easy proof of the differentiability almost everywhere of a monotone function.

He was one of the creators of the theory of subharmonic functions. Other fields to which he contributed include the theory of functions analytic in the unit circle, orthonormal series, inequalities and ergodic theory. He gave several proofs of the fundamental spectral theorem in Hilbert space. An early paper (1908) on topology contains ideas (bicompactness, the filter theory of limits) that had to wait until the late 1930's for their full development.

Riesz's work is characterized throughout by simple and powerful ideas and by lucidity of presentation; his papers are always easy to read. He never generalized for generalization's sake; his aim was always to put the main ideas in a setting that would illustrate their significance and their power as vividly as possible.

F. SMITHIES

\section{Dr. Eugene C. Crittenden}

Eugene Casson Critmenden, formerly associate director of the United States National Bureau of Standards and for many years chief of its Electrical Division, died in Garfield Hospital, Washington, D.C., on March 28 at the age of seventy-five.

After graduating in 1905 and a period of postgraduate work and teaching, all at Cornell, Dr. Crittenden joined the National Bureau of Standards in 1909 and was assigned to the photometric laboratory, where he was afterwards to make many important contributions towards the establishment of modern photometric units, standards and methods of measurement. During 1921-46 he was chief of the Electrical Division and thus also became responsible for work which, in collaboration with other national laboratories, led to the replacement of the obsolescent system of international electrical units by the present system of absolute electrical units. Under his leadership the Division expanded substantially, and sections for research in radio and electronics were established which eventually became major organizational units of the Bureau-for example, the Central Radio Propagation Laboratories at Boulder, Colorado, and the former Ordnance Development Division, now the Diamond Ordnance Fuze Laboratories of the Department of the U.S. Army. In 1933 Dr. Crittenden was made assistant director of the Bureau and became concurrently responsible for supervision of its over-all research and testing activities; and in 1946, when the title was changed to associate director, he assumed the full-time responsibilities of this post, which he held until he retired in 1950. For his outstanding services to the Bureau he was awarded in 1949 one of the first Gold Medals of the Department of Commerce for Exceptional Service. He continued to act as a consultant to the Director of the Bureau until the onset of his last illness a few months ago.

Dr. Crittenden is best known both in his own country and internationally for his many activities and services which, combined with those alroady mentioned, played an important part in the develop. ments which led to the international adoption in 1948 of the present electrical and photometric units and standards. $\mathrm{He}$ was vice-president of the International Commission on Illumination during 1939-48 and president of its U.S. National Committee from 1928 until 1935. During 1946-54 he was the member for the United States on the International Committee of Weights and Measures, of which he was vicepresident from 1950 until 1954, and he had been a member of this Committee's advisory body for electricity and photometry since 1933. He also participated in the work of the International Organization for Standardization and the International Committee of Legal Metrology. Dr. Crittenden was for many years on the Standards Council of the American Standards Association, of which he was chairman during 1945-48, and in his time he served as president of the Illuminating Engineering Society, the U.S. National Committee of the International Electrochemical Commission and the Optical Society of America, as well as associate editor of the Review of Scientific Instruments. He also participated in the work of the American Society for Testing Materials, the American Institute of Electrical Engineers, the American Institute of Physics and the National Research Council.

Dr. Crittenden will long be remembered by his former colleagues on international committees, for he always brought to their deliberations wise counsel based on great knowledge and experience and expounded with good humour. Photometry was the primary interest which eventually led him to become a renowned exponent of international collaboration in all matters concerned with metrology. $\mathrm{He}_{\theta}$ is survived by his wife, formerly Norma M. Snyder, a daughter and a son.

H. BARRELL

\section{Dr. A. L. Stern}

Arthur landauer Stern died suddenly on April 26 at Chorley Wood at the age of eighty-eight. He was born on May 6, 1867, the eldest of seven children of Moritz and Fanny Stern, of Birmingham. At King Edward VI High School he was a Foundation Scholar; and in 1887 from Mason College he obtained honours B.Sc. (London). He was then Tangye Research Scholar and personal assistant under Sir William Tilden, working on compounds of phosphorus. After that, under Dr. Cornelius O'Sullivan, he worked on chemical problems of fermentation and brewing, and soon became chemist and brewer at Messrs. Bass, Ratcliffe and Gretton, under O'Sullivan. An early piece of work was to show that glucose from various sources was tho same substance, and thus he helped to lay one of the foundation stones of modern organic chemistry. He obtained his D.Sc. (London) in 1894.

On the death of O'Sullivan in 1906, Stern succeeded him as head brewer at Bass's New Brewery. He reorganized the research, with prescience concentrating on the biological side (Dr. Arthur Slator was then his chief assistant). Under his direction, the rate of multiplication of yeast cells was shown to be 